\title{
Exposure to Atrazine Induces Lung Inflammation through Nrf2-HO1 and Beclin 1/LC3 Pathways
}

\author{
Ramona D'Amico Francesco Monaco $^{\mathrm{b}}$ Roberta Fusco ${ }^{\mathrm{a}}$ Alessio Filippo Peritore \\ Tiziana Genovese $^{a} \quad$ Daniela Impellizzeria Rosalia Crupic Livia Interdonato ${ }^{a}$ \\ Andrea Maria Sforza ${ }^{a}$ Enrico Gugliandoloc Rosalba Siracusa ${ }^{a}$ \\ Salvatore Cuzzocrea ${ }^{a}$ Marika Cordarob Rosanna Di Paola ${ }^{a}$ \\ aDepartment of Chemical, Biological, Pharmaceutical and Environmental Sciences, University of \\ Messina, Messina, Italy, bepartment of Biomedical, Dental and Morphological and Functional Imaging \\ University of Messina, Messina, Italy, 'Department of Veterinary Sciences, University of Messina, Italy
}

\section{Key Words}

Nrf2 • Autophagy • Oxidative Stress • Endocrine Disruptor • Inflammation

\begin{abstract}
Background/Aims: Atrazine (ATR) is the second most widely used herbicide, after glyphosate, that is used to stop pre- and post-emergence broadleaf and grassy weeds. In 2007, it was included in the class of endocrine disruptors due to the impact its exposure had on human health. Occasional ATR exposure at work has been linked to an increased risk of respiratory problems, but the molecular mechanisms underlying this relationship has not yet been fully elucidated. Methods: Mice were exposed to an aerosol containing ATR. In particular ATR aerosol was prepared by dissolving $250 \mathrm{mg}$ of ATR in a vehicle made with saline and $10 \%$ DMSO. Seven days after the aerosol exposure, the mice were sacrificed and lung tissue, bronchoalveolar lavage fluid (BALF), and blood samples were collected for histology and biochemical analysis. Results: ATR inhalation induces a generalized state of oxidative/nitrosative stress that leads to an increase in cytokines production and to a physiologically unstable antioxidant defense response evaluated by the alteration of Nrf-2 pathways. Moreover, it stimulates autophagy through Beclin 1/Lc3 expressions and increases lipid peroxidation and apoptosis. All these effects culminate in serious alterations in the tissue architecture of the lungs and to an increase in mucus production and mast cells degranulation. Conclusion: Our study shows, for the first time, the impact of ATR inhalation on lung tissue. This could represent the first step to also recognize this substance as a problematic air pollutant as well as a soil and water contaminant.
\end{abstract}

R. D'Amico, F. Monaco and R. Fusco contributed equally to this work.

M. Cordaro and R. Di Paola share senior authorship. 


\section{Introduction}

There is increasing public interest in the effects of endocrine disrupting chemicals on public health, especially the effects of long-term low-dose exposures $[1,2]$. The U.S. Environmental Protection Agency (EPA) has defined an endocrine disruptor (ED) as "an agent that interferes with the synthesis, secretion, transport, binding, or elimination of natural hormones in the body that are responsible for the maintenance of homeostasis, reproduction, development and/or behavior" [3]. Today, this definition is considered to be outdated; in fact, different studies conducted on animals as well as clinical observations and epidemiological studies have indicated that endocrine disruptors can affect reproductive systems, prostate, breast, liver, thyroid, metabolism, and lungs [4, 5]. EDs can be classified into the following three different groups: (i) food contact materials such as bisphenol A, (ii) chemicals in products such as phthalates or parabens, and (iii) pesticides such as atrazine (ATR) $[6,7]$. Methods for predicting effects on populations and societies based on knowledge of effects on individuals must be established in order to understand the vulnerability and risk factors of people due to endocrine disruptors, as well as treatments approaches [2].

Every year, four million people die prematurely as a result of chronic respiratory diseases, 300 million people have asthma, and 210 million people have chronic obstructive pulmonary disease (COPD) [8-10]. As a result of this situation, stakeholders have advocated for a stronger battle against the main risk factors for respiratory diseases, such as air pollution [11, 12]. Occupational exposure to pesticides occurs during their production, transport, and storage; during user's preparation and application; as well as, during re-entry into treated fields, harvests, and equipment cleaning $[13,14]$. The majority of pesticides used in agriculture enter the body through the skin, followed by the respiratory and oral paths. Inhalation of pesticides is most common during fumigation, mixture preparation, and/or application in enclosed spaces [15-18]. Occupational exposure of farmers, farm employees, and pesticide manufacturing industry workers may be the most important, and it has been extensively studied, but para-occupational and residential exposure are also worthy of consideration $[15,19-21]$.

The chemical name for ATR is 6-chloro-N-ethyl-N'-(1-methylethyl)-1,3,5-triazine-2,4diamine, and it is the most commonly used broad-spectrum herbicide in agricultural crops such as corn, sorghum, and sugarcane [22]. Despite the fact that farm use of ATR is limited in the EU, it is still one of the most widely used pesticides in the world, with ATR being found in ground water in the United States and Europe on a regular basis [22, 23]. ATR has a halflife of 95-350 days and is resistant to degradation; in fact, following application, it can be present in the particulate and vapor phases of the air, and it can travel up to 186 miles from the application site [24]. Atrazine can be broken down in the air by reacting with hydroxyl radicals $[25,26]$. ATR contamination has been linked to many different serious health issues such as dermatologic diseases, neurologic conditions, cancer, and respiratory problems [2737]. In particular, the Agricultural Health Study (AHS), one of the most important studies of respiratory pathologies, found a correlation between wheeze and atrazine exposure $(>20$ days per year, OR 1.53, 95 percent CI 1.21-1.95) [38].

However, until today, few reports have explored the molecular mechanisms underlying ATR induction of lung problems. Some of the most accredited hypothesis that could explain the mechanism of toxicity induced by ATR is the production of reactive oxygen species (ROS) $[22,39-43]$. In particular, some of the study results that prompted us to investigate the ways by which ATR exerts its lung toxicity were the discovery by Zhao and colleagues that ATR could induce a response activated by nuclear factor erythroid 2-related factors 2 (Nrf2); the increase in the malondialdehyde levels as well as in the activities of superoxide dismutase (SOD), catalase (CAT), and glutathione peroxidase (GPx) found by Batti et al.; and finally the results by Song et al. that demonstrated that ATR enhanced the apoptotic and autophagic processes $[22,39,44]$. These studies (and many others) have in common the fact that ATR was administered by oral gavage. However, considering that some ATR is released into the atmosphere as a result of its preparation, manufacturing, and disposal, and that it also enters 


\section{Cellular Physiology Cell Physiol Biochem 2021;55:413-427 \\ \begin{tabular}{ll|l} 
and Biochemistry $10.33594 / 000000393$ & $\begin{array}{l}\text { O } 2021 \text { The Author(s). Published by } \\
\text { Cell Physiol Biochem Press GmbH\&Co. KG }\end{array}$ \\
\cline { 2 - 3 } & Published online: 7 July 2021 &
\end{tabular} \\ D'Amico et al.: Atrazine Inhalation Induces Lung Damage}

the environment through the loss of applied herbicide until it enters the soil surface, as well as the particle distribution of ATR-containing dust, and considering that ATR volatilization after application to fields has been estimated to be up to $14 \%$ of the applied volume, it is critical to investigate the effects in the lungs of occasional air exposure. Understanding the molecular basis of ATR-induced oxidative stress, apoptosis, and autophagic processes is critical for the development of therapeutic approaches to limit compromised lung function. With this aims in our mind, we investigated for the first time the impact of ATR aerosol inhalation.

\section{Materials and Methods}

\section{Animals}

CD1 male mice (8 weeks old, 18-24 g) were acquired from Envigo (Milan, Italy) and located in a controlled environment. The study was approved by the Review Board of the University of Messina for the care of animals. In addition, the experiments on mice complied with U.S. (Animal Welfare Insurance No. A5594-01, Department of Health and Human Services, Washington, DC, USA), European (OJ of ECL 358/1 12/18/1986), and Italian (DM 116192) regulations.

\section{Experimental Design and Groups}

The ATR aerosol was prepared by dissolving $250 \mathrm{mg}$ of ATR in a vehicle made with saline and $10 \%$ DMSO. After complete solubilization, a Lovelace nebulizer (In-Tox Products, Albuquerque, NM, USA) was used to create an atmosphere in an exposure chamber (Research and Consulting Co., AG, Basel, Switzerland) $[45,46]$. In detail, each mouse was carefully inserted into an animal tube with the nose pointing to the aerosol outlet. The animal tubes were specifically designed to contain one mouse per tube. Using the plunger in the tube, the mouse was gently immobilized in the correct position. This phase was very important to allow the animal to breathe properly. After being immobilized, a known volume of vehicle or ATR (pro kilo) was placed in the nebulization until it was completely nebulized.

The mice were randomly divided into the following two groups:

(I) Sham group, i.e., animals that were exposed to the vehicle (saline with $10 \%$ of DMSO).

(II) ATR group, i.e., animals that were exposed to $250 \mathrm{mg}$ of ATR for 1 hour for 1 day.

After exposure, the mice were housed in individual cages (six per cage) and maintained under a 12:12 hours light/dark cycle at $21 \pm 1{ }^{\circ} \mathrm{C}$ and $50 \pm 5 \%$ humidity. Standard laboratory litter, diet, and water were available ad libitum. Additionally, the mice were weighted and observed for any clinical symptoms, and the information was recorded by the animal care staff. Seven days after the aerosol exposure, the mice were sacrificed and lung tissue, bronchoalveolar lavage fluid (BALF), and blood samples were collected for histology and biochemical analysis, as previously described [40, 42, 43, 47-49]. The ATR dosage was chosen based on other previous studies, but for the first time, ATR was not administered by oral gavage but instead by aerosol, because there is still limited knowledge of the effects of ATR on the lungs [50-52].

\section{Western Blot Analysis of Cytosolic and Nuclear Extracts}

Extracts of the cytosol and nucleus were prepared, as previously mentioned [53-57]. The following primary antibodies were used: anti-NRF-2 (1:500, Santa Cruz Biotechnology, Heidelberg, Germany, \#sc365949), anti-heme oxygenase 1 (HO-1; 1:500, Santa Cruz Biotechnology, Heidelberg, Germany, \#sc136960), anti-Bax (1:500, Santa Cruz Biotechnology, \#sc7480), anti-Bcl-2 (1:500, Santa Cruz Biotechnology, \#sc7382), anti-Beclin 1 (1:500, Santa Cruz Biotechnology, \#sc48341), and anti-MAPLC3 (1:500, Santa Cruz Biotechnology, \#sc271625) in $1 \times$ PBS, $5 \%$ w/v non-fat dried milk, and $0.1 \%$ Tween 20 , at $4{ }^{\circ} \mathrm{C}$ overnight. For the cytosolic fraction, Western blots were also probed with antibody against $\beta$-actin protein to ensure that they were filled with equivalent amounts of proteins (1:500, Santa Cruz Biotechnology). The same methods were used for nuclear fraction with lamin A/C (1:500, Sigma-Aldrich Corp., Milan, Italy). Signals were examined with an enhanced chemiluminescence (ECL) detection system reagent, according to the manufacturer's instructions (Thermo, Monza, Italy). The relative expression of the protein bands was quantified by densitometry with BIORAD ChemiDocTM XRS ${ }^{+}$software and standardized to the $\beta$-actin and lamin A/C levels. 


\section{Cellular Physiology and Biochemistry \\ Cell Physiol Biochem 2021;55:413-427 \\ \begin{tabular}{l|l}
\hline DOI: 10.33594/000000393 & ( 2021 The Author(s). Published by
\end{tabular} \\ D'Amico et al.: Atrazine Inhalation Induces Lung Damage}

Histopathological Evaluation with Hematoxylin/Eosin, Toluidine Blue, and Periodic Acid Schiff

The lung tissues were dehydrated, embedded in paraffin, stained with hematoxylin and eosin (H\&E) and toluidine blue, and analyzed using a light microscopy (Leica DM6, Milan, Italy) associated with an Imaging system (LasX Navigator, Milan, Italy); lung tissues were blindly scored and mast cells counted by two investigators. The degree of inflammation was evaluated according to a score from 1 to 3 , as previously described [58, 59]. The mast cell counts were assessed, as previously described by Fusco et al. [60]. Lung tissue was also analyzed with PAS to assess goblet cell hyperplasia according to a score from 0 to 4 , as previously described by Wang et al. [58, 59].

\section{Evaluation of Tissue Lipid Peroxidation}

Malonaldehyde (MDA) levels was assessed, as previously described for lung tissue, at the end of the experiments. Briefly, after homogenization, MDA absorbances was measured at $650 \mathrm{~nm}$, using a spectrophotometer and expressed in mill-units per 100 milligram weights $(\mathrm{mU} / 100 \mathrm{mg})$ of wet tissue [6167].

\section{Assessment of Plasma Parameters}

ELISA kits were used to test the activity of superoxide dismutase (SOD), glutathione peroxidase (GPx), catalase (CAT), reactive oxygen species (ROS), reactive nitrogen species (RNS), and hydrogen peroxide $\left(\mathrm{H}_{2} \mathrm{O}_{2}\right)$ in plasma, as previously described [68]. The manufacturer's manuals provided specific instructions for the test procedure. Every test were made in triplicate.

\section{Assessment of Cytokines Production}

ELISA kits were used to test the inflammatory cytokine production, in particular IL-1 $\beta$, IL-6, IL-18, IL-10, and IL-4, in BALF after ATR induction, as previously described [69]. The manufacturer's manuals provided specific instructions for the test procedure. Every test were made in triplicate.

\section{Materials}

Unless otherwise stated, all compounds were purchased from Sigma-Aldrich (city, country).

\section{Statistical Evaluation}

In this study, the data are expressed as the average \pm SEM and represent at least 3 experiments carried out in different days. For in vivo studies, $\mathrm{N}$ represents the number of animals used. The number of animals used for in vivo studies was carried out by G * Power 3.1 software (Die Heinrich-Heine-Universität Düsseldorf, Düsseldorf, Germany). Data were analyzed by an experienced histopathologist, and all the studies were performed without knowledge of the treatments. The results were analyzed by t-tests followed by two-tailed calculations. Group data are normalized to mean values for mice. Homoscedasticity not been assessed. A $p$-value less than 0.05 was considered to be significant.

\section{Results}

\section{ATR Induces a Generalized State of Oxidative/Nitrosative Stress}

In the plasma, through the ELISA analysis, we found that a generalized state of oxidative and nitrosative stress was established which would probably spread through the blood as well as into other parts of the body. In particular, we found that ATR induced a significant increase in ROS (Fig. 1A), $\mathrm{H}_{2} \mathrm{O}_{2}$ (Fig. 1B), and RNS (Fig. 1C) as compared with animals not exposed to ATR.

\section{ATR Exposure Enhanced Cytokines Production}

Through the use of ELISA kits, on the one hand, we found that ATR exposure increased the level of proinflammatory cytokines in BALF, in particular, IL-13 (Fig. 2A), IL-6 (Fig. 2B), and IL-18 (Fig. 2C) and, on the other hand, we found a significant decrease in anti-inflammatory cytokines IL-10 (Fig. 2D) and IL-4 (Fig. 2E) as compared with the sham groups. 
ATR Exposure Compromised the Physiological Antioxidant Response

In order to further investigate how ATR induced the antioxidant response of cells, by Western blot analysis, we investigated the expression of Nrf2 and HO-1 in lung tissue and, consequently, by ELISA kits, we also investigated the stimulation of antioxidant enzymes in plasma. We found that ATR stimulated the physiological response of Nrf2 expression (Fig. $3 \mathrm{~A}$, see densitometric analysis Fig. $3 \mathrm{~A}^{\prime}$ ) as compared with the sham group. Similar results were found by the analysis of the expression of HO-1 (Fig. 3B, see densitometric analysis Fig. $\left.3 \mathrm{~B}^{\prime}\right)$, one of the most important enzymes regulated by Nrf2. Additionally, ATR stimulates the body's physiological antioxidant defense trying to fight the establishment of a generalized condition of oxidative stress. In particular, it increases the activity of CAT (Fig. 3C) as well as of SOD (Fig. 3D) and GPx (Fig. 3E).

Fig. 1. Exposure to ATR induces oxidative/nitrosative stress conditions. (A) ROS; (B) H2O2; (C) RNS. By ELISA kits, in the plasma, we found that ATR exposure induced a significant generalized state of oxidative/nitrosative stress. Values are means \pm SEM of 6 mice for all groups. Each experiment was repeated 3 times on 3 different days. Group data are normalized to mean values for mice. Each sample was loaded in triplicate. See manuscript for further details. ${ }^{* * *} \mathrm{p}<0.001$ vs. sham and ${ }^{* *} \mathrm{p}<0.01$ vs. sham.

Fig. 2. Exposure to ATR affects cytokine production. (A) IL-1 $\beta$; (B) IL-6; (C) IL-18; (D) IL-10; (E) IL-4. ATR administration was characterized by an increase in several proinflammatory cytokines and a decrease in anti-inflammatory cytokines into the BALF as compared with the sham group. Values are means \pm SEM of 6 mice for all group. See manuscript for further details. ${ }^{* * *} \mathrm{p}<0.001$ vs. sham.
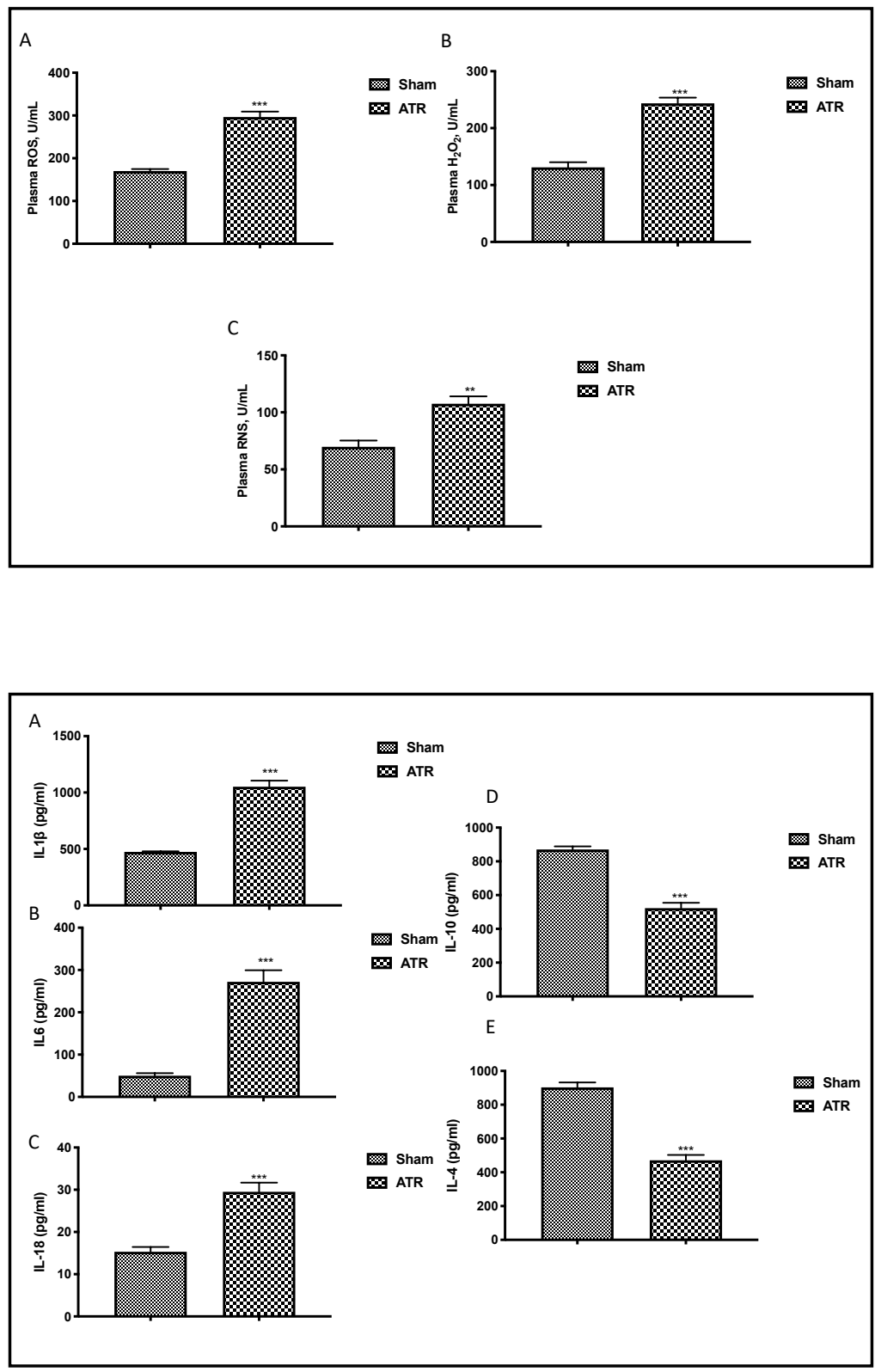
Fig. 3. Exposure to ATR induces limits to antioxidant defense. Western blots and quantification of lung tissue from NRF2 (A and $\mathrm{A}^{\prime}$ ) and HO-1 (B and $B^{\prime}$ ), respectively. ELISA kits of CAT (C), SOD (D), and GPx (E) levels after ATR administration. Values are means \pm SEM of 6 mice for all groups. Each experiment was repeated 3 times on 3 different days. Group data are normalized to mean values for mice. Each sample was loaded in triplicate. See manuscript for further details. *** $\mathrm{p}<0.001$ vs. sham and $* * \mathrm{p}<0.01$ vs. sham.

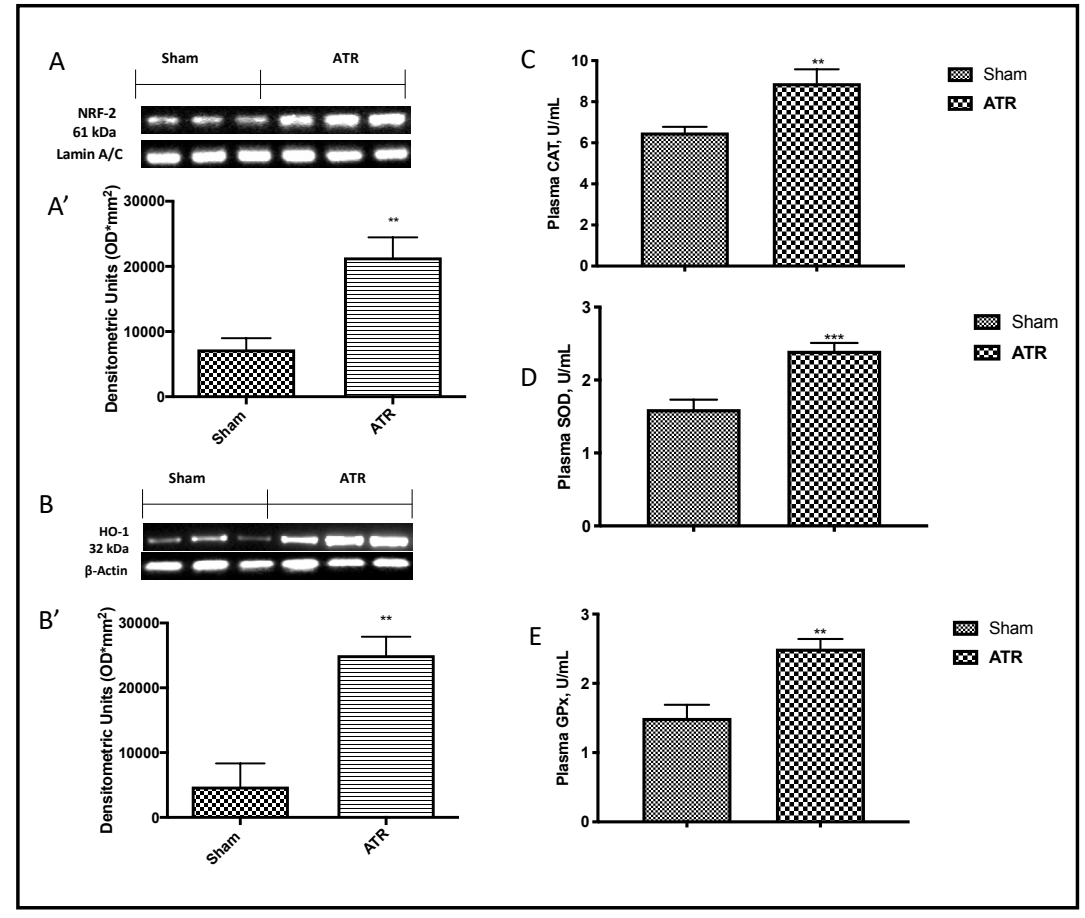

ATR Stimulates Autophagy through Beclin 1/LC3 Expressions

Microtubule-associated protein light chain 3 (LC3) and Beclin 1 are specific marker proteins of autophagy; therefore, we investigated them by Western blot analysis. In our study, we found that ATR stimulates the initiation of the autophagic process, as demonstrated by an increase in Beclin 1 (Fig. 4A and densitometric analysis Fig. 4A') and LC3 (Fig. 4B and densitometric analysis Fig. 4B') expressions.

\section{ATR Induces Lipid Peroxidation and Apoptosis}

Therefore, we investigated the effect of ATR in lung tissue by MDA levels and by Western blot for Bax and Bcl-2, As expected, on the one hand, we found a significant increase in lipid peroxidation as well as in pro-apoptotic protein Bax (Fig. 5B and densitometric analysis Fig. $5 \mathrm{~B}^{\prime}$ ), on the other hand, we found a decrease in anti-apoptotic Bcl-2 (Fig. 5C and densitometric analysis Fig. 5C')

\section{Effects of ATR Administration on Lung Tissue}

Finally, we directly investigated alterations in lung tissue. We found that, after ATR administration, lung tissue (Fig. 6B and high magnification Fig. 6B', see score Fig. 6C) appeared to be significantly inflamed as compared with the sham group (Fig. 6A and high magnification Fig. 6A', see score Fig. 6C). In order to better understand the effect of ATRinduced airway inflammation, we also performed PAS staining. On the one hand, there were no pathological changes observed in the lung tissue of the control group (Fig. 2A, see score Fig. 2B). On the other hand, after ATR exposure, we found significant goblet cell proliferation in the bronchial epithelium with increased production and secretion of mucus (Fig. 7A', see score Fig. 7B). Additionally, we decided to investigate whether mast cells were also recalled to the lungs following exposure to ATR. As previously highlighted by Mizoda and Ueda [70], we found that ATR induced significant mast cell recall following exposure (Fig. 7C', see score Fig. 7D)., which headed towards the site of inflammation and also underwent significant degranulation, as evidenced by the staining. No degranulated mast cells were found in the control animals (Fig. 7C, see score Fig. 7D). 


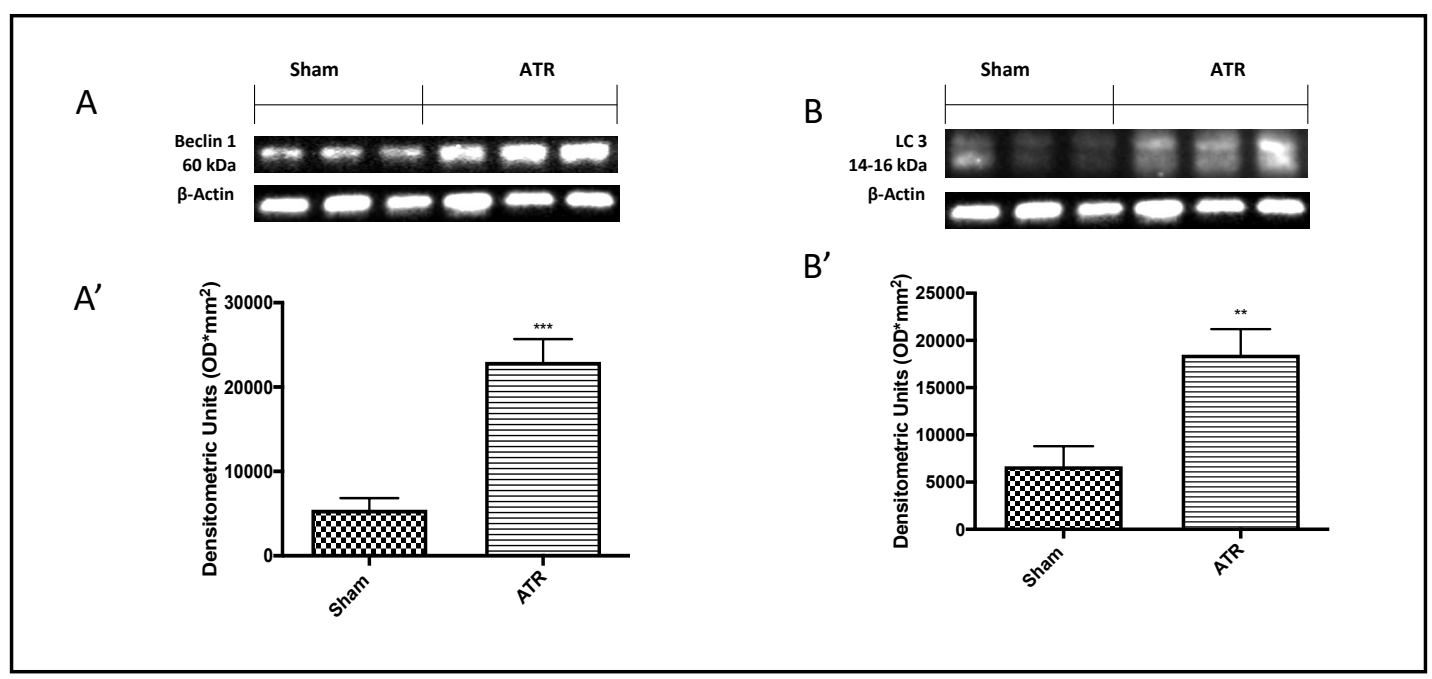

Fig. 4. Exposure to ATR increases Beclin 1 and LC3 expressions. Western blots and quantification of lung tissue from Beclin 1 (A and A') and LC3 (B and B'), respectively, after ATR administration. Values are means \pm SEM of 6 mice for all groups. Each experiment was repeated 3 times on 3 different days. Each sample was loaded in triplicate. Group data are normalized to mean values for mice. The photo shown is representative of the results obtained. See manuscript for further details. ${ }^{* * *} \mathrm{p}<0.001$ vs. sham and ${ }^{* *} \mathrm{p}<0.01$ vs. sham.

Fig. 5. Exposure to ATR induces lipid peroxidation and apoptosis. MDA (A) and Western blots, respectively, quantification of lung tissue for Bax (B and B') and Bcl-2 (C and $C^{\prime}$ ) after ATR administration. Values are means \pm SEM of 6 mice for all groups. Each experiment was repeated 3 times on 3 different days. Each sample was loaded in triplicate. Group data are normalized to mean values for mice. The photo shown is representative of the results obtained. See manuscript for further details. ** $\mathrm{p}<0.01$ vs. sham.

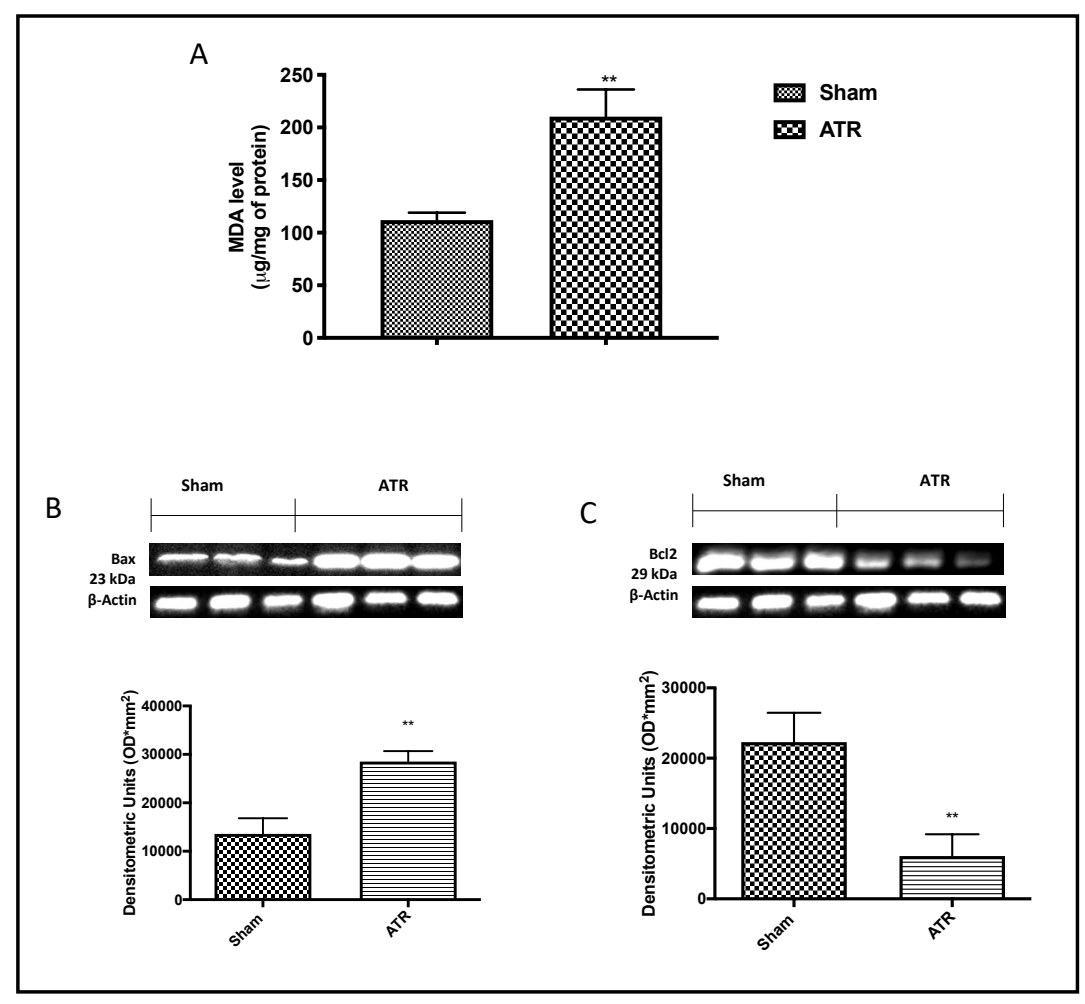


Fig. 6. Effects of ATR exposure on lung tissue. Hematoxylin/eosin on lung tissue. (A and $A^{\prime}$ ) sham group; (B and B') ATR group. After ATR exposure, inflammatory cells, edema, and lung tissue architecture alterations were evident in the ATR group. Values are means \pm SEM of 6 mice for all group. Group data are normalized to mean values for mice. The photo shown is representative of the results obtained. See manuscript for further details. ${ }^{* * *} \mathrm{p}<0.001$ vs. sham.

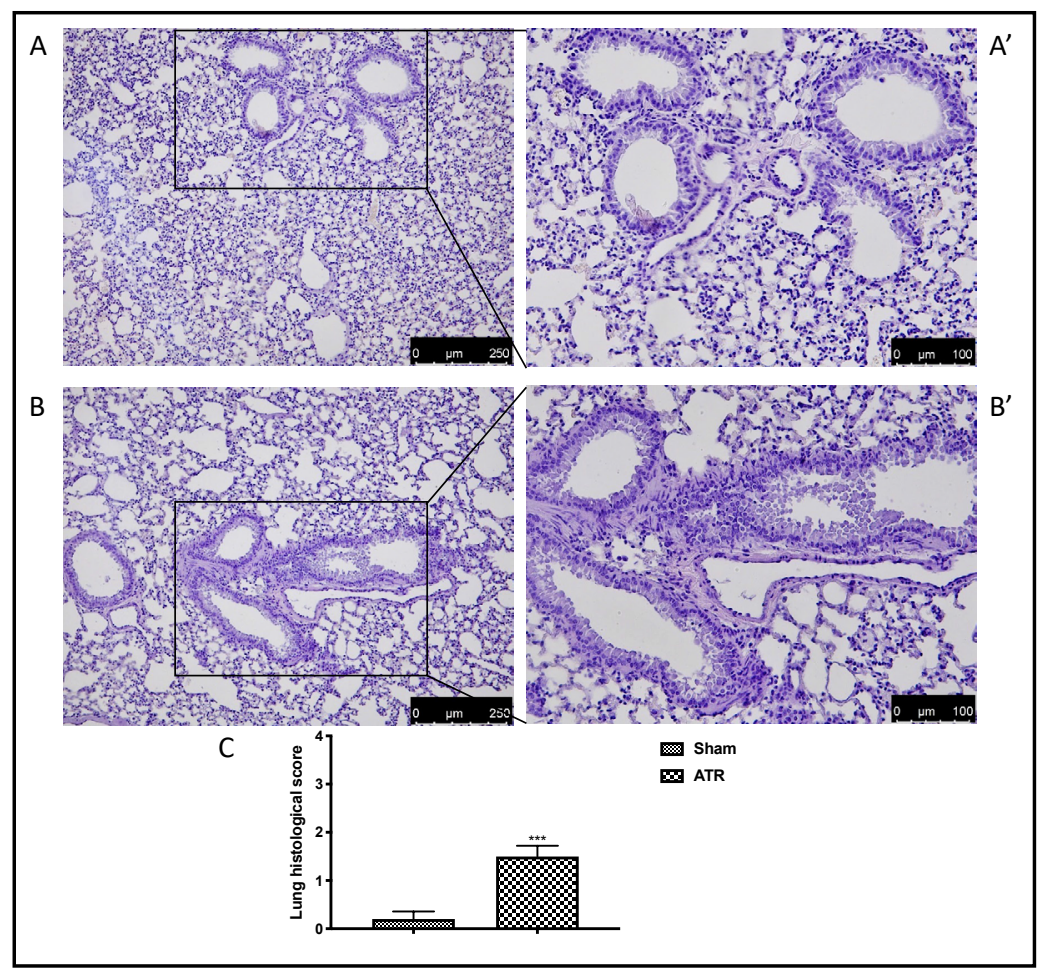

Fig. 7. Effects of ATR on goblet and mast cells. PAS staining on lung tissue. (A) sham; (A') ATR; (B) PAS score. Toluidine blue staining on lung tissue. (C) sham; (C') ATR; (D) mast cells count. PAS staining highlighted, in the ATR group, a marked goblet cell hyperplasia with increased mucus production and secretion. Additionally, by toluidine blue, we observed that ATR exposure was able to increase mast cells degranulation as compared with the sham group. Values are means \pm SEM of 6 mice for all group. Group data are normalized to mean values for mice. The photo shown is representative of the results obtained.

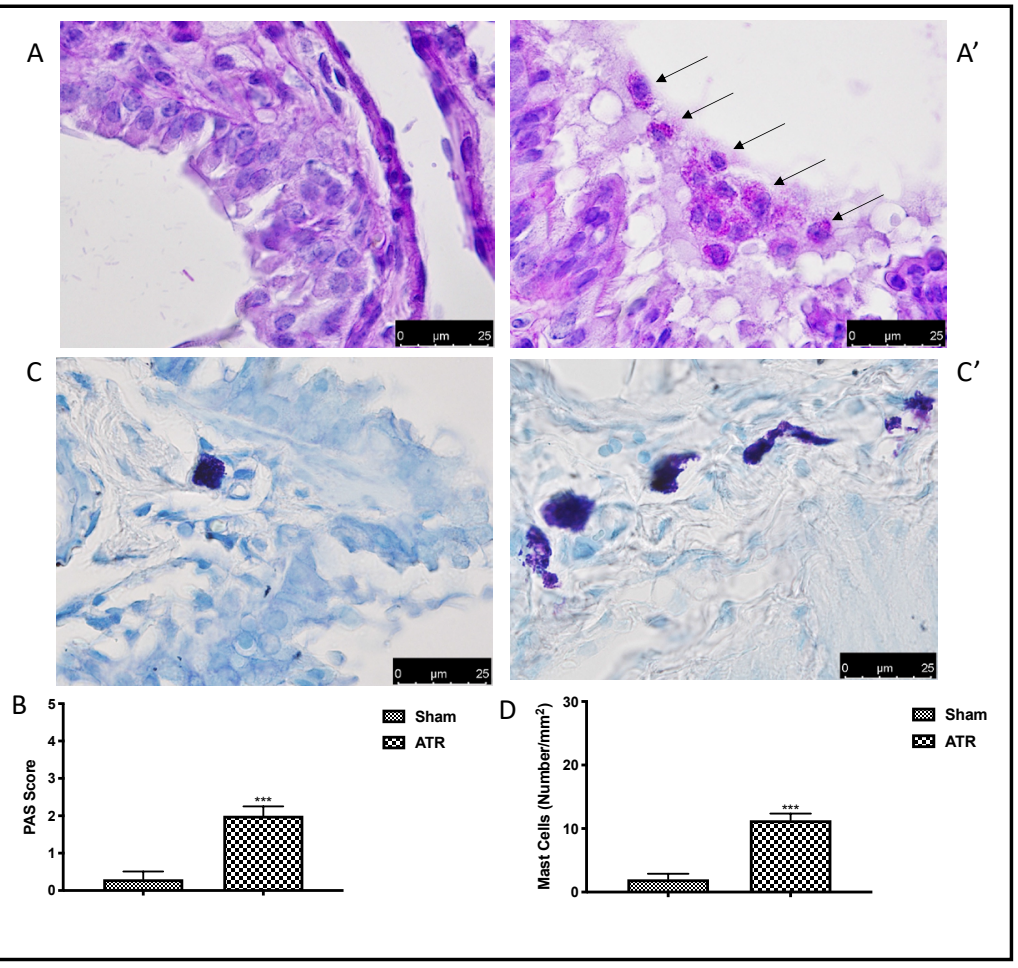
See manuscript for further details. ${ }^{* * *} \mathrm{p}<0.001$ vs. sham. 


\section{Discussion}

ATR is a commonly used herbicide for controlling broadleaf weeds. It is a man-made compound that does not exist naturally and is widely used on corn crops in the United States and Europe. The total projected agricultural use in the United States is 76.4 million pounds per year, with corn accounting for 86 percent of that total [71]. The United States Environmental Protection Agency (EPA) has designated ATR as a restricted use pesticide (RUP), meaning that only licensed herbicide users can purchase or use it due to its persistence in water and various adverse health effects on humans. The maximum contamination level (MCL) for atrazine is set at $3 \mathrm{ppb}(0.003 \mathrm{~g} / \mathrm{L})$ by EPA regulations [71]. Unlike the United States, Europe has stricter regulations on the use of ATR. A pesticide directive issued by the European Union (EU), in 1991, restricted the use of chemicals that were accused of causing harm to human health, groundwater, or the atmosphere. In addition, during acceptable usage, the scientific committee examining atrazine found, in 2003, that the herbicide had the potential to contaminate groundwater levels above the permitted $0.1 \mathrm{~g} / \mathrm{L}$. As a result of this discovery, a regulatory ban on ATR was enacted in 2005, affecting all EU member states. As a result, Europe is embarking on a continent-wide agricultural experiment without the use of ATR [72]. Significant quantities of ATR that are not absorbed by plants do end up in the environment. ATR is only weakly adsorbed by soil particles after application, and thus mainly leaves the field in runoff water. Rainfall washes large quantities of ATR out of the soil and into nearby areas, such as streams, reservoirs, and other waterways. Moreover, after it is added to the soil, small quantities of ATR may reach the air [73]. Humans are mainly exposed to ATR by the intake of tainted drinking water. However, inhalation exposure may occur during application on rare occasions. ATR's negative effects are still being studied [74]. In humans, increased risk of intrauterine growth retardation, decreased semen content, and spontaneous abortions were found in many peer-reviewed studies, as were demasculinization and hermaphrodism in frogs [75-79]. In particular, it has been demonstrated that ATR can induce oxidative stress conditions following an imbalanced condition of physiological antioxidant $[39,42,47,70,80,81]$.

Oxidative stress is characterized as an imbalance between oxidant and antioxidant species in a system where oxidant species predominate [82]. It has only recently been studied as a potential mediator of ED-related outcomes [83-85]. Many oxidative stress measurements can be collected using minimally invasive methods, for example, in blood, making these methods reasonably simple to use in both animal and human studies [86]. Our first results demonstrate the onset of a generalized state of increased oxidative and nitrosative stress. The respiratory system regulate and express inflammatory pathways in such a way that the respiratory system's primary functions are preserved, while still protecting it from invasion by foreign infective agents or antigens. A previous study has shown that oxidative stress can act as an initiator of cytokine release and cell damage [87]. Cytokines, which are expressed by a variety of cells ranging from immune cells like macrophages and lymphocytes to endothelial cells and fibroblasts, during inflammation, act as communicators between immune cells for regulating cell growth, maturation, and responsiveness [88, 89]. In particular, several cytokines are released from monocytes and macrophages, and recruit neutrophils into lung tissues, which is vital for host defense and contributes to the development of lung injury $[90,91]$. On the other hands, IL-4 and IL-10, which are potent anti-inflammatory cytokines, could suppress the activity of many inflammatory molecules $[91,92]$. Our study demonstrated, for the first time, that inhalation of ATR, on the one hand, significantly enhanced the release of proinflammatory cytokines and, on the other hand, reduced the production of anti-inflammatory cytokines. In order to preserve redox homeostasis in the cell, ROS and RNS are counterbalanced by complex antioxidant systems. SOD, CAT, and GPx are the most important antioxidant protagonists involved in this response initiated by the cells. Nrf2, which is stimulated with HO-1 in the case of an imbalance in physiological/pathological ROS production, is one of these regulatory networks [93-95]. Nrf2 is a transcription factor that is present in epithelium and alveolar macrophages but 


\section{Cellular Physiology Cell Physiol Biochem 2021;55:413-427

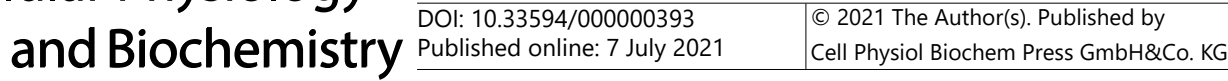 \\ D'Amico et al.: Atrazine Inhalation Induces Lung Damage}

is primarily expressed in the lungs. Recent studies have shown that Nrf2 protects the lungs from oxidative insults such as high oxygen stress and particulates in the air. The activation of ARE-regulated antioxidant genes, whose products work directly or indirectly to restrict ROS-mediated pulmonary pathogenesis, is thought to be the mechanism of Nrf2-mediated defense [96]. In our study. we confirmed that following exposure to inhaled ATR, cells carry out the physiological response that involves increasing the expression of Nrf2 levels, as well as HO-1, SOD, CAT, and GPx in lungs and plasma. Autophagy can operate as a degradative pathway for oxidatively modified substrates such as proteins and phospholipids, acting as a general cellular protective mechanism against oxidative stress. Since mitochondria are both an intracellular source of ROS and a functional target for ROS generation, autophagy's role in mitochondrial homeostasis may be crucial during oxidative stress [97-99]. For this reason, in the pathogenesis of inflammatory diseases, autophagic clearance may be a critical host response mechanism [100]. Beclin 1 and LC3 are specific marker proteins of autophagy, as well as important regulators of autophagy [101-103]. By Western blot analysis, first, we investigated two of the most common markers used to understand the autophagic process, Beclin 1 and LC3, and the apoptotic process with Bax and Bcl-2 expression. Our results indicate that occasional inhaled exposure to atrazine stimulates autophagy by inducing autophagosome formation and also induces apoptosis by increasing the expression of the pro-apoptotic protein Bax and by reducing the expression of the anti apoptotic protein Bcl- 2 . Recently, different studies have focused their attention on the effect of occasional pesticide exposure and respiratory pathology. In fact, it has been demonstrated that people who deal with pesticides have been found to have deteriorated pulmonary function [104]. However, until today, this mechanism has remained unclear. Wheezing, airway inflammation, dry/sore throat, cough, breathlessness, and chest tightness are some of the respiratory symptoms linked to pesticide exposure, which are linked with modifications in the tissue architecture of the lungs [105-107]. We demonstrated that, following ATR exposure, the lungs undergo a series of structural changes with an increase in mucus secretion.

\section{Conclusion}

Taken together, our data significantly increase the understanding of the mechanisms of immunotoxicity of ATR in the lungs. In particular, we demonstrate, for the first time, that as well as oral administration of ATR can induce serious ROS-related damage, also inhalation can have a similar effect. This could also represent the first step for recognizing that this substance is a problematic air pollutant.

\section{Acknowledgements}

\section{Author Contributions}

Conceptualization, M.C. and R.S.; formal analysis, A.F.P. and T.G.; investigation, R.D-A. L.I. and A.M.S.; methodology, E.G. and R.C.; project administration, S.C. and R.D.P.; supervision, F.M. and R.D.P.; validation, R.F. and D.I.; writing—review and editing, R.F. and M.C.

\section{Funding Sources}

This research was supported in part by the Ministero dell'Istruzione, dell'Università e della Ricerca (MIUR), PRIN 2017 (Prot. 2017MLC3NF).

\section{Disclosure Statement}

The authors declare no conflict of interests exists. 


\section{Cellular Physiology Cell Physiol Biochem 2021;55:413-427

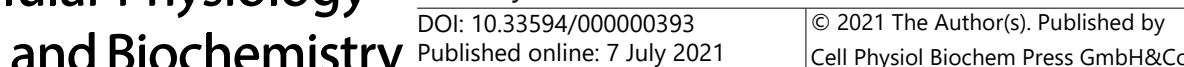 \\ D'Amico et al.: Atrazine Inhalation Induces Lung Damage}

\section{References}

1 Veerasingam SA, Ali Mohd M: Assessment of endocrine disruptors - DDTs and DEHP (plasticizer) in source water: a case study from Selangor, Malaysia. J Water Health 2013;11:311-323.

2 Kabir ER, Rahman MS, Rahman I: A review on endocrine disruptors and their possible impacts on human health. Environ Toxicol Pharmacol 2015;40:241-258.

3 Kavlock RJ, Daston GP, DeRosa C, Fenner-Crisp P, Gray LE, Kaattari S, Lucier G, Luster M, Mac MJ, Maczka C, Miller R, Moore J, Rolland R, Scott G, Sheehan DM, Sinks T, Tilson HA: Research needs for the risk assessment of health and environmental effects of endocrine disruptors: a report of the U.S. EPA-sponsored workshop. Environ Health Perspect 1996;104:715-740.

4 Derghal A, Djelloul M, Trouslard J, Mounien L: An Emerging Role of micro-RNA in the Effect of the Endocrine Disruptors. Front Neurosci 2016;10:318.

5 Polyzos SA, Kountouras J, Deretzi G, Zavos C, Mantzoros CS: The emerging role of endocrine disruptors in pathogenesis of insulin resistance: a concept implicating nonalcoholic fatty liver disease. Curr Mol Med 2012;12:68-82.

6 Koch CA, Diamanti-Kandarakis E: Introduction to Endocrine Disrupting Chemicals--is it time to act? Rev Endocr Metab Disord 2015;16:269-270.

7 Dodson RE, Nishioka M, Standley LJ, Perovich LJ, Brody JG, Rudel RA: Endocrine disruptors and asthmaassociated chemicals in consumer products. Environ Health Perspect 2012;120:935-943.

8 Ferkol T, Schraufnagel D: The global burden of respiratory disease. Ann Am Thorac Soc 2014;11:404-406.

9 Barnes PJ, Blasi F, Ward B, Reeves E, Rabe KF: Respiratory diseases in the world: one voice "united for lung health". Eur Respir J 2014;43:3-5.

10 World Health Organization: WHO Report on the Global Tobacco Epidemic, 2008: The MPOWER package. Geneva, World Health Organization, 2008. URL: https://www.who.int/tobacco/mpower/mpower_report full_2008.pdf

11 Schraufnagel D: The world respiratory diseases report. Int J Tuberc Lung Dis 2013;17:1517.

12 Pawankar R, Baena-Cagnani CE, Bousquet J, Walter Canonica G, Cruz AA, Kaliner MA, Lanier BQ: State of world allergy report 2008 allergy and chronic respiratory diseases. World Allergy Organ J 2008;1:S1.

13 Dalphin JC: [Respiratory pathology in the agricultural environment]. Rev Prat 1998;48:1313-1318.

14 Hoppin JA, Umbach DM, London SJ, Alavanja MC, Sandler DP: Animal production and wheeze in the Agricultural Health Study: interactions with atopy, asthma, and smoking. Occup Environ Med 2003;60:e3.

15 Bradman A, Quiros-Alcala L, Castorina R, Aguilar Schall R, Camacho J, Holland NT, Barr DB, Eskenazi B: Effect of Organic Diet Intervention on Pesticide Exposures in Young Children Living in Low-Income Urban and Agricultural Communities. Environ Health Perspect 2015;123:1086-1093.

16 Duramad P, Harley K, Lipsett M, Bradman A, Eskenazi B, Holland NT, Tager IB: Early environmental exposures and intracellular Th1/Th2 cytokine profiles in 24-month-old children living in an agricultural area. Environ Health Perspect 2006;114:1916-1922.

17 Eskenazi B, Bradman A, Castorina R: Exposures of children to organophosphate pesticides and their potential adverse health effects. Environ Health Perspect 1999;107:409-419.

18 Abelsohn A, Sanborn MD, Jessiman BJ, Weir E: Identifying and managing adverse environmental health effects: 6. Carbon monoxide poisoning. CMAJ 2002;166:1685-1690.

19 Maroni M, Fanetti AC, Metruccio F: Risk assessment and management of occupational exposure to pesticides in agriculture. Med Lav 2006;97:430-437.

20 Baldi I, Lebailly P, Rondeau V, Bouchart V, Blanc-Lapierre A, Bouvier G, Canal-Raffin M, Garrigou A: Levels and determinants of pesticide exposure in operators involved in treatment of vineyards: results of the PESTEXPO Study. J Expo Sci Environ Epidemiol 2012;22:593-600.

21 Salvatore AL, Castorina R, Camacho J, Morga N, Lopez J, Nishioka M, Barr DB, Eskenazi B, Bradman A: Home-based community health worker intervention to reduce pesticide exposures to farmworkers' children: A randomized-controlled trial. J Expo Sci Environ Epidemiol 2015;25:608-615.

22 Song XY, Li JN, Wu YP, Zhang B, Li BX: Atrazine Causes Autophagy- and Apoptosis-Related Neurodegenerative Effects in Dopaminergic Neurons in the Rat Nigrostriatal Dopaminergic System. Int J Mol Sci 2015;16:13490-13506.

23 Guzzella L, Pozzoni F, Giuliano G: Herbicide contamination of surficial groundwater in Northern Italy. Environ Pollut 2006;142:344-353. 


\section{Cellular Physiology Cell Physiol Biochem 2021;55:413-427 \begin{tabular}{ll|l} 
and Biochemistry $10.33594 / 000000393$ & $\begin{array}{l}\text { Published online: } 7 \text { July } 2021 \\
\text { Cell Physiol Biochem Press GmbH\&Co. KG }\end{array}$
\end{tabular}

24 Abraxis L, Kit AE, Kit AT: Immunoassay Test Kits for Atrazine. URL: https://swap.stanford. edu/20110531024456/http://www.epa.gov/etv/pubs/600s07016.pdf.

25 United States Environmental Protection Agency (EPA): Interim Reregistration Eligibility Decision for Atrazine, Appendices C and K. Washington, DC, 2003.

26 Filipov NM, Pinchuk LM, Boyd BL, Crittenden PL: Immunotoxic Effects of Short-term Atrazine Exposure in Young Male C57BL/6 Mice. Toxicol Sci 2005;86:324-332.

27 Singh M, Kaur P, Sandhir R, Kiran R: Protective effects of vitamin E against atrazine-induced genotoxicity in rats. Mutat Res 2008;654:145-149.

28 Atrazine and Breast Cancer: A Framework Assessment of the Toxicological and Epidemiological Evidence. Toxicol Sci 2017;159:480.

29 Inoue-Choi M, Weyer PJ, Jones RR, Booth BJ, Cantor KP, Robien K, Ward MH: Atrazine in public water supplies and risk of ovarian cancer among postmenopausal women in the Iowa Women's Health Study. Occup Environ Med 2016;73:582-587.

30 Hu K, Tian Y, Du Y, Huang L, Chen J, Li N, Liu W, Liang Z, Zhao L: Atrazine promotes RM1 prostate cancer cell proliferation by activating STAT3 signaling. Int J Oncol 2016;48:2166-2174.

31 Albanito L, Lappano R, Madeo A, Chimento A, Prossnitz ER, Cappello AR, Dolce V, Abonante S, Pezzi V, Maggiolini M: Effects of atrazine on estrogen receptor alpha- and G protein-coupled receptor 30-mediated signaling and proliferation in cancer cells and cancer-associated fibroblasts. Environ Health Perspect 2015;123:493-499.

32 Boffetta P, Adami HO, Berry SC, Mandel JS: Atrazine and cancer: a review of the epidemiologic evidence. Eur J Cancer Prev 2013;22:169-180.

33 Freeman LE, Rusiecki JA, Hoppin JA, Lubin JH, Koutros S, Andreotti G, Zahm SH, Hines CJ, Coble JB, Barone-Adesi F, Sloan J, Sandler DP, Blair A, Alavanja MC: Atrazine and cancer incidence among pesticide applicators in the agricultural health study (1994-2007). Environ Health Perspect 2011;119:1253-1259.

34 McElroy JA, Gangnon RE, Newcomb PA, Kanarek MS, Anderson HA, Brook JV, Trentham-Dietz A, Remington PL: Risk of breast cancer for women living in rural areas from adult exposure to atrazine from well water in Wisconsin. J Expo Sci Environ Epidemiol 2007;17:207-214.

35 Rusiecki JA, De Roos A, Lee WJ, Dosemeci M, Lubin JH, Hoppin JA, Blair A, Alavanja MC: Cancer incidence among pesticide applicators exposed to atrazine in the Agricultural Health Study. J Natl Cancer Inst 2004;96:1375-1382.

36 Hessel PA, Kalmes R, Smith TJ, Lau E, Mink PJ, Mandel J: A nested case-control study of prostate cancer and atrazine exposure. J Occup Environ Med 2004;46:379-385.

37 Van Leeuwen JA, Waltner-Toews D, Abernathy T, Smit B, Shoukri M: Associations between stomach cancer incidence and drinking water contamination with atrazine and nitrate in Ontario (Canada) agroecosystems, 1987-1991. Int J Epidemiol 1999;28:836-840.

38 Hoppin JA, Umbach DM, London SJ, Alavanja MC, Sandler DP: Chemical predictors of wheeze among farmer pesticide applicators in the Agricultural Health Study. Am J Respir Crit Care Med 2002;165:683-689.

39 Zhao F, Li K, Zhao L, Liu J, Suo Q, Zhao J, Wang H, Zhao S: Effect of Nrf2 on rat ovarian tissues against atrazine-induced anti-oxidative response. Int J Clin Exp Pathol 2014;7:2780-2789.

40 Lin J, Xia J, Zhao HS, Hou R, Talukder M, Yu L, Guo JY, Li JL: Lycopene Triggers Nrf2-AMPK Cross Talk to Alleviate Atrazine-Induced Nephrotoxicity in Mice. J Agric Food Chem 2018;66:12385-12394.

41 Rezaie Agdam H, Razi M, Amniattalab A, Malekinejad H, Molavi M: Co-Administration of Vitamin E and Testosterone Attenuates The Atrazine-Induced Toxic Effects on Sperm Quality and Testes in Rats. Cell J 2017;19:292-305.

42 Liu W, Du Y, Liu J, Wang H, Sun D, Liang D, Zhao L, Shang J: Effects of atrazine on the oxidative damage of kidney in Wister rats. Int J Clin Exp Med 2014;7:3235-3243.

43 Gao S, Wang Z, Zhang C, Jia L, Zhang Y: Oral Exposure to Atrazine Induces Oxidative Stress and Calcium Homeostasis Disruption in Spleen of Mice. Oxid Med Cell Longev 2016;2016:7978219.

44 Bhatti JS, Sidhu IP, Bhatti GK: Ameliorative action of melatonin on oxidative damage induced by atrazine toxicity in rat erythrocytes. Mol Cell Biochem 2011;353:139-149.

45 Schramm CM, Puddington L, Wu C, Guernsey L, Gharaee-Kermani M, Phan SH, Thrall RS: Chronic inhaled ovalbumin exposure induces antigen-dependent but not antigen-specific inhalational tolerance in a murine model of allergic airway disease. Am J Pathol 2004;164:295-304. 


\section{Cellular Physiology Cell Physiol Biochem 2021;55:413-427 \begin{tabular}{l|l|l} 
DOl: $10.33594 / 000000393$ & O 2021 The Author(s). Published by \\
and Biochemistry Published online: 7 July 2021 & Cell &
\end{tabular} \\ D'Amico et al.: Atrazine Inhalation Induces Lung Damage}

46 Vaughan RP, Szewczyk MT, Jr., Lanosa MJ, Desesa CR, Gianutsos G, Morris JB: Adenosine sensory transduction pathways contribute to activation of the sensory irritation response to inspired irritant vapors. Toxicol Sci 2006;93:411-421.

47 Zhang X, Wang M, Gao S, Ren R, Zheng J, Zhang Y: Atrazine-induced apoptosis of splenocytes in BALB/C mice. BMC Med 2011;9:117.

$48 \mathrm{Li} \mathrm{J}$, Li X, Bi H, Ma K, Li B: Developmental Exposure to Atrazine Impairs Spatial Memory and Downregulates the Hippocampal D1 Dopamine Receptor and cAMP-Dependent Signaling Pathway in Rats. Int J Mol Sci 2018;19:2241.

49 Secor Jr ER, Carson 4th WF, Cloutier MM, Guernsey LA, Schramm CM, Wu CA, Thrall RS: Bromelain exerts anti-inflammatory effects in an ovalbumin-induced murine model of allergic airway disease. Cell Immunol 2005;237:68-75.

50 Filipov NM, Pinchuk LM, Boyd BL, Crittenden PL: Immunotoxic effects of short-term atrazine exposure in young male C57BL/6 mice. Toxicol Sci 2005;86:324-332.

51 Lin Z, Dodd CA, Filipov NM: Short-term atrazine exposure causes behavioral deficits and disrupts monoaminergic systems in male C57BL/6 mice. Neurotoxicol Teratol 2013;39:26-35.

52 Coban A, Filipov NM: Dopaminergic toxicity associated with oral exposure to the herbicide atrazine in juvenile male C57BL/6 mice. J Neurochem 2007;100:1177-1187.

53 Cordaro M, Paterniti I, Siracusa R, Impellizzeri D, Esposito E, Cuzzocrea S: KU0063794, a Dual mTORC1 and mTORC2 Inhibitor, Reduces Neural Tissue Damage and Locomotor Impairment After Spinal Cord Injury in Mice. Mol Neurobiol 2017;54:2415-2427.

54 Siracusa R, Impellizzeri D, Cordaro M, Crupi R, Esposito E, Petrosino S, Cuzzocrea S: Anti-Inflammatory and Neuroprotective Effects of Co-UltraPEALut in a Mouse Model of Vascular Dementia. Front Neurol 2017;8:233.

55 Campolo M, Esposito E, Ahmad A, Di Paola R, Paterniti I, Cordaro M, Bruschetta G, Wallace JL, Cuzzocrea S: Hydrogen sulfide-releasing cyclooxygenase inhibitor ATB-346 enhances motor function and reduces cortical lesion volume following traumatic brain injury in mice. J Neuroinflammation 2014;11:196.

56 Cordaro M, Impellizzeri D, Gugliandolo E, Siracusa R, Crupi R, Esposito E, Cuzzocrea S: Adelmidrol, a Palmitoylethanolamide Analogue, as a New Pharmacological Treatment for the Management of Inflammatory Bowel Disease. Mol Pharmacol 2016;90:549-561.

57 Di Paola R, Cordaro M, Crupi R, Siracusa R, Campolo M, Bruschetta G, Fusco R, Pugliatti P, Esposito E, Cuzzocrea S: Protective Effects of Ultramicronized Palmitoylethanolamide (PEA-um) in Myocardial Ischaemia and Reperfusion Injury in VIVO. Shock 2016;46:202-213.

58 Wang S, Yang Y, Luo D, Wu D, Liu H, Li M, Sun Q, Jia L: Lung inflammation induced by exposure to Bisphenol-A is associated with mTOR-mediated autophagy in adolescent mice. Chemosphere 2020;248:126035.

59 Fusco R, Siracusa R, D’Amico R, Cordaro M, Genovese T, Gugliandolo E, Peritore AF, Crupi R, Di Paola R, Cuzzocrea S, Impellizzeri D: Mucosa-Associated Lymphoid Tissue Lymphoma Translocation 1 Inhibitor as a Novel Therapeutic Tool for Lung Injury. Int J Mol Sci 2020;21:7761.

60 Fusco R, Cordaro M, Genovese T, Impellizzeri D, Siracusa R, Gugliandolo E, Peritore AF, D’Amico R, Crupi R, Cuzzocrea S, Di Paola R: Adelmidrol: A New Promising Antioxidant and Anti-Inflammatory Therapeutic Tool in Pulmonary Fibrosis. Antioxidants 2020;9:601.

61 Cuzzocrea S, Mazzon E, Esposito E, Muia C, Abdelrahman M, Di Paola R, Crisafulli C, Bramanti P, Thiemermann C: Glycogen synthase kinase-3beta inhibition attenuates the development of ischaemia/ reperfusion injury of the gut. Intensive Care Med 2007;33:880-893.

62 Costantino G, Cuzzocrea S, Mazzon E, Caputi AP: Protective effects of melatonin in zymosan-activated plasma-induced paw inflammation. Eur J Pharmacol 1998;363:57-63.

63 Impellizzeri D, Esposito E, Di Paola R, Ahmad A, Campolo M, Peli A, Morittu VM, Britti D, Cuzzocrea S: Palmitoylethanolamide and luteolin ameliorate development of arthritis caused by injection of collagen type II in mice. Arthritis Res Ther 2013;15:R192.

64 Fusco R, D’Amico R, Cordaro M, Gugliandolo E, Siracusa R, Peritore AF, Crupi R, Impellizzeri D, Cuzzocrea S, Di Paola R: Absence of formyl peptide receptor 1 causes endometriotic lesion regression in a mouse model of surgically-induced endometriosis. Oncotarget 2018;9:31355-31366. 


\section{Cellular Physiology Cell Physiol Biochem 2021;55:413-427 \begin{tabular}{l|l|l} 
DOl: $10.33594 / 000000393$ & O 2021 The Author(s). Published by \\
and Biochemistry Published online: 7 July 2021 & Cell Physion Bioch
\end{tabular} \\ D'Amico et al.: Atrazine Inhalation Induces Lung Damage}

65 Gugliandolo E, D’Amico R, Cordaro M, Fusco R, Siracusa R, Crupi R, Impellizzeri D, Cuzzocrea S, Di Paola R: Effect of PEA-OXA on neuropathic pain and functional recovery after sciatic nerve crush. J Neuroinflammation 2018;15:264.

66 D’Amico R, Fusco R, Gugliandolo E, Cordaro M, Siracusa R, Impellizzeri D, Peritore AF, Crupi R, Cuzzocrea S, Di Paola R: Effects of a new compound containing Palmitoylethanolamide and Baicalein in myocardial ischaemia/reperfusion injury in vivo. Phytomedicine 2019;54:27-42.

67 Cordaro M, Impellizzeri D, Siracusa R, Gugliandolo E, Fusco R, Inferrera A, Esposito E, Di Paola R, Cuzzocrea S: Effects of a co-micronized composite containing palmitoylethanolamide and polydatin in an experimental model of benign prostatic hyperplasia. Toxicol Appl Pharmacol 2017;329:231-240.

68 Zhu K, Zhao Y, Yang Y, Bai Y, Zhao T: Icariin Alleviates Bisphenol A Induced Disruption of Intestinal Epithelial Barrier by Maintaining Redox Homeostasis In Vivo and In Vitro. ACS Omega 2020;5:2039920408.

69 An X, Sun X, Hou Y, Yang X, Chen H, Zhang P, Wu J: Protective effect of oxytocin on LPS-induced acute lung injury in mice. Sci Rep 2019;9:2836.

70 Mizota K, Ueda H: Endocrine disrupting chemical atrazine causes degranulation through Gq/11 proteincoupled neurosteroid receptor in mast cells. Toxicol Sci 2006;90:362-368.

71 United States Envinronmental Protection Agency: Atrazine Monitoring Program Data and Results, 2008. URL: https://www.epa.gov/ingredients-used-pesticide-products/atrazine-monitoring-program-data-andresults.

72 Ackerman F: The economics of atrazine. Int J Occup Environ Health 2007;13:437-445.

73 Agency for Toxic Substances and Disease Registry (ATSDR): Interaction profile for arsenic, cadmium, chromium and lead. Atlanta, Georgia: U.S. Department of Health and Human Services, Public Health Service, 2006. URL: https://www.atsdr.cdc.gov/interactionprofiles/ip10.html.

74 Kavlock R: Overview of endocrine disruptor research activity in the United States. Chemosphere 1999;39:1227-1236.

75 Munger R, Isacson P, Hu S, Burns T, Hanson J, Lynch CF, Cherryholmes K, Van Dorpe P, Hausler WJ Jr: Intrauterine growth retardation in Iowa communities with herbicide-contaminated drinking water supplies. Environ Health Perspect 1997;105:308-314.

76 Arbuckle TE, Lin Z, Mery LS: An exploratory analysis of the effect of pesticide exposure on the risk of spontaneous abortion in an Ontario farm population. Environ Health Perspect 2001;109:851-857.

77 Hayes TB, Collins A, Lee M, Mendoza M, Noriega N, Stuart AA, Vonk A: Hermaphroditic, demasculinized frogs after exposure to the herbicide atrazine at low ecologically relevant doses. Proc Natl Acad Sci U S A 2002;99:5476-5480.

78 Swan SH: Semen quality in relation to pesticide exposure in Missouri males. Mo Med 2003;100:554.

79 Swan SH, Kruse RL, Liu F, Barr DB, Drobnis EZ, Redmon JB, Wang C, Brazil C, Overstreet JW, Study for Future Families Research G: Semen quality in relation to biomarkers of pesticide exposure. Environ Health Perspect 2003;111:1478-1484.

80 Abarikwu SO: Protective effect of quercetin on atrazine-induced oxidative stress in the liver, kidney, brain, and heart of adult wistar rats. Toxicol Int 2014;21:148-155.

81 Jestadi DB, Phaniendra A, Babji U, Srinu T, Shanmuganathan B, Periyasamy L: Effects of short term exposure of atrazine on the liver and kidney of normal and diabetic rats. J Toxicol 2014;2014:536759.

82 Lushchak VI: Free radicals, reactive oxygen species, oxidative stress and its classification. Chem Biol Interact 2014;224:164-175.

83 Badham HJ, Renaud SJ, Wan J, Winn LM: Benzene-initiated oxidative stress: Effects on embryonic signaling pathways. Chem Biol Interact 2010;184:218-221.

84 Shono T, Taguchi T: Short-time exposure to mono-n-butyl phthalate (MBP)-induced oxidative stress associated with DNA damage and the atrophy of the testis in pubertal rats. Environ Sci Pollut Res Int 2014;21:3187-3190.

85 Sulkowski ZL, Chen T, Midha S, Zavacki AM, Sajdel-Sulkowska EM: Maternal thimerosal exposure results in aberrant cerebellar oxidative stress, thyroid hormone metabolism, and motor behavior in rat pups; sexand strain-dependent effects. Cerebellum 2012;11:575-586.

86 Neier K, Marchlewicz EH, Dolinoy DC, Padmanabhan V: Assessing Human Health Risk to Endocrine Disrupting Chemicals: a Focus on Prenatal Exposures and Oxidative Stress. Endocr Disruptors (Austin) 2015;3:e1069916. 


\section{Cellular Physiology Cell Physiol Biochem 2021;55:413-427

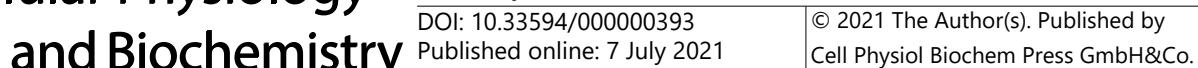 \\ D'Amico et al.: Atrazine Inhalation Induces Lung Damage}

87 Crapo JD: Oxidative stress as an initiator of cytokine release and cell damage. Eur Respir J Suppl 2003;44:4s-6s.

88 Dinarello CA: Historical insights into cytokines. Eur J Immunol 2007;37:S34-45.

89 Akdis M, Aab A, Altunbulakli C, Azkur K, Costa RA, Crameri R, Duan S, Eiwegger T, Eljaszewicz A, Ferstl R, Frei R, Garbani M, Globinska A, Hess L, Huitema C, Kubo T, Komlosi Z, Konieczna P, Kovacs N, Kucuksezer UC, et al.: Interleukins (from IL-1 to IL-38), interferons, transforming growth factor beta, and TNF-alpha: Receptors, functions, and roles in diseases. J Allergy Clin Immunol 2016;138:984-1010.

90 Szarka RJ, Wang N, Gordon L, Nation PN, Smith RH: A murine model of pulmonary damage induced by lipopolysaccharide via intranasal instillation. J Immunol Methods 1997;202:49-57.

91 Wojdasiewicz P, Poniatowski LA, Szukiewicz D: The role of inflammatory and anti-inflammatory cytokines in the pathogenesis of osteoarthritis. Mediators Inflamm 2014;2014:561459.

92 Bazzoni F, Tamassia N, Rossato M, Cassatella MA: Understanding the molecular mechanisms of the multifaceted IL-10-mediated anti-inflammatory response: lessons from neutrophils. Eur J Immunol 2010;40:2360-2368.

93 Ma Q: Role of nrf2 in oxidative stress and toxicity. Annu Rev Pharmacol Toxicol 2013;53:401-426.

94 Cordaro M, Siracusa R, Impellizzeri D, R DA, Peritore AF, Crupi R, Gugliandolo E, Fusco R, Di Paola R, Schievano C, Cuzzocrea S: Safety and efficacy of a new micronized formulation of the ALIAmide palmitoylglucosamine in preclinical models of inflammation and osteoarthritis pain. Arthritis Res Ther 2019;21:254.

95 Peritore AF, Siracusa R, Fusco R, Gugliandolo E, D’Amico R, Cordaro M, Crupi R, Genovese T, Impellizzeri D, Cuzzocrea S, Di Paola R: Ultramicronized Palmitoylethanolamide and Paracetamol, a New Association to Relieve Hyperalgesia and Pain in a Sciatic Nerve Injury Model in Rat. Int J Mol Sci 2020;21:3509.

96 Cho HY, Reddy SP, Kleeberger SR: Nrf2 defends the lung from oxidative stress. Antioxid Redox Signal 2006;8:76-87.

97 Zhang J: Autophagy and Mitophagy in Cellular Damage Control. Redox Biol 2013;1:19-23.

98 Kubli DA, Gustafsson AB: Mitochondria and mitophagy: the yin and yang of cell death control. Circ Res 2012;111:1208-1221.

99 Ryter SW, Choi AM: Autophagy in lung disease pathogenesis and therapeutics. Redox Biol 2015;4:215-225.

100 Mizumura K, Cloonan S, Choi ME, Hashimoto S, Nakahira K, Ryter SW, Choi AM: Autophagy: Friend or Foe in Lung Disease? Ann Am Thorac Soc 2016;13:S40-47.

101 Sui X, Li Y, Sun Y, Li C, Li X, Zhang G: Expression and significance of autophagy genes LC3, Beclin1 and MMP2 in endometriosis. Exp Ther Med 2018;16:1958-1962.

102 Di Paola R, Impellizzeri D, Fusco R, Cordaro M, Siracusa R, Crupi R, Esposito E, Cuzzocrea S: Ultramicronized palmitoylethanolamide (PEA-um((R))) in the treatment of idiopathic pulmonary fibrosis. Pharmacol Res 2016;111:405-412.

103 Fusco R, Siracusa R, Peritore AF, Gugliandolo E, Genovese T, D’Amico R, Cordaro M, Crupi R, Mandalari G, Impellizzeri D, Cuzzocrea S, Di Paola R: The Role of Cashew (Anacardium occidentale L.) Nuts on an Experimental Model of Painful Degenerative Joint Disease. Antioxidants 2020;9:511.

104 Lozier MJ, Montoya JF, Del Rosario A, Martinez EP, Fuortes L, Cook TM, Sanderson WT: Personal air sampling and risks of inhalation exposure during atrazine application in Honduras. Int Arch Occup Environ Health 2013;86:479-488.

105 Ye M, Beach J, Martin JW, Senthilselvan A: Occupational pesticide exposures and respiratory health. Int J Environ Res Public Health 2013;10:6442-6471.

106 Gugliandolo E, Fusco R, Ginestra G, D’Amico R, Bisignano C, Mandalari G, Cuzzocrea S, Di Paola R: Involvement of TLR4 and PPAR-alpha Receptors in Host Response and NLRP3 Inflammasome Activation, Against Pulmonary Infection With Pseudomonas Aeruginosa. Shock 2019;51:221-227.

107 Travelli C, Aprile S, Rahimian R, Grolla AA, Rogati F, Bertolotti M, Malagnino F, di Paola R, Impellizzeri D, Fusco R, Mercalli V, Massarotti A, Stortini G, Terrazzino S, Del Grosso E, Fakhfouri G, Troiani MP, Alisi MA, Grosa G, Sorba G, et al.: Identification of Novel Triazole-Based Nicotinamide Phosphoribosyltransferase (NAMPT) Inhibitors Endowed with Antiproliferative and Antiinflammatory Activity. J Med Chem 2017;60:1768-1792. 